\title{
QTL Mapping Identifies Novel Source of Resistance to Fusarium Wilt Race 1 in Citrullus amarus
}

\author{
Sandra E. Branham, Amnon Levi, and W. Patrick Wechter ${ }^{\dagger}$ \\ U.S. Vegetable Laboratory, USDA-ARS, Charleston, SC 29414
}

\begin{abstract}
Fusarium wilt race 1, caused by the soilborne fungus Fusarium oxysporum Schlechtend.: Fr. f. sp. niveum (E.F. Sm.) W.C. Snyder \& H.N. Hans (Fon), is a major disease of watermelon (Citrullus lanatus) in the United States and throughout the world. Although Fusarium wilt race 1 resistance has been incorporated into several watermelon cultivars, identification of additional genetic sources of resistance is crucial if a durable and sustainable level of resistance is to be continued over the years. We conducted a genetic mapping study to identify quantitative trait loci (QTLs) associated with resistance to Fon race 1 in

segregating populations $\left(\mathrm{F}_{2: 3}\right.$ and recombinant inbred lines) of Citrullus amarus (citron melon) derived from the Fon race 1 resistant and susceptible parents USVL246-FR2 and USVL114, respectively. A major QTL ( $q$ Fon 1-9) associated with resistance to Fon race 1 was identified on chromosome 9 of USVL246-FR2. This discovery provides a novel genetic source of resistance to Fusarium wilt race 1 in watermelon and, thus, an additional host-resistance option for watermelon breeders to further the effort to mitigate this serious phytopathogen.
\end{abstract}

Watermelon is an economically important crop with over 45,000 ha grown in the United States in 2016 (USDA-ERS 2017), yielding 18.2 million kilograms with a total farm gate value of $\$ 578.8$ million. Today, seedless varieties occupy over $85 \%$ of the U.S. watermelon market. However, seedless varieties, typically begun as transplanted seedlings, require special care to avoid soilborne disease. The soilborne fungal pathogen Fusarium oxysporum Schlechtend.: Fr. f. sp. niveum (Fon) causes Fusarium wilt of watermelon. Fusarium wilt is considered the most important soilborne disease of watermelon, limiting production worldwide through yield loss and plant death. Fusarium wilt is characterized by foliar chlorosis, necrosis, wilting, and unilateral stem necrosis (Kleczewski and Egel 2011). A recent resurgence in the incidence of Fusarium wilt of watermelon highlights the need for more effective control measures of this important disease.

Disease management of Fusarium wilt includes long crop rotations, soil fumigants, host-plant resistance, and grafting onto resistant root stocks (Everts and Himmelstein 2015). Crop rotations are difficult to implement for most watermelon producers owing to the long duration required, because Fon has been shown to remain viable in soil for more than 10 years (Martyn 1987). Everts et al. (2014) found that either prothioconazole or thiophanate-methyl can reduce the severity of Fusarium wilt in watermelon, but their efficacy was inconsistent and required multiple applications to the soil over the growing season. Grafting onto rootstocks of other cucurbit species suppresses infection from the host-specific Fon (Keinath and Hassell 2014a, b) and can increase yield (Colla

${ }^{\dagger}$ Corresponding author: W. P. Wechter; E-mail: Pat.Wechter@USDA.gov

Funding: This study was funded by the United States Department of Agriculture, Agricultural Research Service, project no. 6080-22000-025-00 and the National Institute of Food and Agriculture, project no. 6080-21000-018-08. This research used resources provided by the SCINet project of the USDA Agricultural Research Service, ARS project number 0500-00093-001-00-D.

*The $\boldsymbol{e}$-Xtra logo stands for "electronic extra" and indicates that three supplementary tables are published online.

Accepted for publication 12 August 2018.

This article is in the public domain and not copyrightable. It may be freely reprinted with customary crediting of the source. The American Phytopathological Society, 2019. et al. 2006), but it increases crop production costs. Ultimately, any highly effective control program will need to use host-plant resistance to Fon, which requires the continual incorporation of new resistance sources to circumvent the breakdown of R-genemediated resistance (Staskawicz et al. 1995).

Four pathogenic Fon races $(0,1,2$, and 3$)$ have been identified, all of which have been reported in the United States (Martyn and Bruton 1989; Martyn and Netzer 1991; Netzer 1976; Netzer and Martyn 1989; Zhou et al. 2010). Resistance to Fon race 1 has been incorporated into many diploid cultivars. Inheritance studies suggest the action of a single dominant gene (Netzer and Weintall 1980), which was delimited to the distal region of chromosome 1 through quantitative trait locus (QTL) mapping (Lambel et al. 2014; Meru and McGregor 2016; Ren et al. 2015).

Although resistance to Fon race 1 has been well studied, identification of additional sources and gene loci conferring resistance would be beneficial for breeding through gene pyramiding of Fon race 1 resistance. Incorporating multiple $\mathrm{R}$ genes into commercial watermelon germplasm would have the potential to both increase levels of resistance and slow the breakdown of host resistance by pathogens (Kiyosawa 1982). Intensive selection pressure during the domestication of watermelon (Citrullus lanatus) has eroded genetic diversity (Levi et al. 2013) and led to the loss of many disease resistance genes and alleles that still remain in the more genetically diverse citron melon (C. amarus) (Guo et al. 2013; Levi et al. 2001). Resistance to Fon race 2 was recently reported in $C$. amarus plant introductions (Wechter et al. 2012, 2016), which may provide a source of additional resistance alleles for introgression into cultivated watermelon. Although citron melon was recently reclassified from a subspecies of $C$. lanatus (subsp. citroides) to a separate species $C$. amarus (Chomicki and Renner 2015), it crosses readily with C. lanatus and can therefore be utilized in watermelon breeding programs (Levi et al. 2013).

Here, we describe QTL mapping of Fon race 1 resistance in segregating $\mathrm{F}_{2: 3}$ and recombinant inbred line (RIL) populations derived from Fon race 1 resistant and susceptible lines of $C$. amarus. The major QTL for Fon race 1 resistance identified in the present study differs from that identified in both $C$. lanatus (Lambel et al. 2014; Meru and McGregor 2016) and C. amarus (Ren et al. 2015).

\section{Materials and Methods}

Plant materials and experimental design. A C. amarus $\mathrm{F}_{2: 3}$ population was produced by hand pollination from a cross between the 
Fon race 1 resistant parent USVL246-FR2 (Wechter et al. 2016) and the susceptible parent USVL114, as described previously (Branham et al. 2017). Single-seed descent of the $F_{2}$ population was used to generate a RIL ( $F_{6}$ to $F_{8}$ ) population segregating for resistance to Fon race 1.

The parents, $\mathrm{F}_{1}$, and $180 \mathrm{~F}_{2: 3}$ families were tested for resistance to Fon race 1 using a randomized complete block design in three greenhouse tests with two replicates of 10 plants each. The tests were planted in December 2016, January 2017, and December 2017 and maintained in the same greenhouse with temperatures ranging from 28 to $35^{\circ} \mathrm{C}$. The parents, $\mathrm{F}_{1}$, and RIL population ( $n$ $=203$ ) were planted and maintained in a greenhouse test in August $2017\left(28\right.$ to $\left.38^{\circ} \mathrm{C}\right)$ with a randomized block design of two replicates of five plants each. Fon race differentials, including the cultivars Sugar Baby, Charleston Gray, Calhoun Gray, and All Sweet and C. amarus accession PI296341-FR, were included with each replicate for race confirmation. Additionally, the race 1 designation of the Fon isolate used in this work was subjected to molecular characterization by polymerase chain reaction (PCR) using the primer set described by Niu et al. (2016), modified as follows: for a $10 \mu \mathrm{l}$ reaction, $2 \mu \mathrm{l}$ of $5 \times$ Promega buffer, $0.2 \mu \mathrm{l}$ of $10 \mathrm{mM}$ dNTP mix (Applied Bioscience, Forest City, CA), $1 \mu \mathrm{l}$ each of $10 \mu \mathrm{M}$ FonSIX6 F and FonSIX6 R primers, and $0.05 \mu \mathrm{l}$ of Promega Go Taq polymerase (Promega, Madison, WI). Thermal cycling conditions were as follows: $95^{\circ} \mathrm{C}$ for $3 \mathrm{~min} ; 30$ cycles of $94^{\circ} \mathrm{C}$ for $1 \mathrm{~min}$, $66^{\circ} \mathrm{C}$ for $1 \mathrm{~min}$, and $72^{\circ} \mathrm{C}$ for $1 \mathrm{~min}$; and a final extension of $72^{\circ} \mathrm{C}$ for $10 \mathrm{~min}$.

Inoculations and disease evaluation. Inoculation of populations was performed using a seed-based inoculation protocol previously described by Wechter et al. (2012). In brief, seeds were planted into a trimix of potting material (Metromix 360 [Sun Gro Horticulture, Agawam, MA]/vermiculite [Therm-o-rock East, New Eagle, PA]/ perlite [Therm-o-rock East], 1:1:1) that had been saturated with a Fon race 1 spore suspension in tap water at a concentration of $1 \times 10^{6}$ conidia/ml. Fifty-cell propagation trays (Protrays; Hummert International, Earth City, MO) were filled with the saturated trimix. Seeds of each family and RIL were individually seeded, one seed per cell, into the trimix. Each set of 10 seeds of $F_{2: 3}$ individuals or five seeds per RIL was replicated twice (i.e., 20 seeds per family or 10 seeds per RIL per test were evaluated). Disease evaluations were conducted at 28 days postinoculation for each test. The $\mathrm{F}_{3}$ families were rated for percent survival. Completely wilted plants were considered dead and symptomless or mildly chlorotic plants rated as alive. RILs were given a disease severity score of 1 to 5 to provide a rating more representative of the range of disease symptoms observed. The disease severity scale was as follows: $1=$ asymptomatic plants; $2=$ slight chlorosis of cotyledons; $3=$ one or both cotyledons wilted, with no stem browning; $4=$ both cotyledons wilted, with stem browning; and $5=$ dead.

Statistical analysis. Each replicate was filtered to exclude samples with low germination rate (removed samples if fewer than four of the 10 seeds $\left[\mathrm{F}_{2: 3}\right]$ or three of the five seeds [RILs] germinated) to provide a representative mean for each genotype. Fon race 1 resistance ratings (i.e., the percentage of surviving $\mathrm{F}_{3}$ individuals in each $\mathrm{F}_{2: 3}$ family) were partitioned into variance components with ASReml-R version 3.0 (Gilmour et al. 2009) using a restricted maximum likelihood algorithm to fit a linear mixed model. The model included family, test, the interaction of family and test, and replicate nested within test as random effects. Broad-sense heritability $\left(\mathrm{H}^{2}\right)$ of Fon race 1 resistance was calculated as the family variance component divided by the sum of all variance components in the model. Pearson's correlation coefficient $(r)$ was calculated with the stats package of $\mathrm{R}$ (R Core Team 2017) to examine the correlation of Fon race 1 resistance between replicates and between tests. Homogeneity of variances across tests was assessed with Levene's test (Levene 1960) using the car package (Fox and Weisberg 2011) in $\mathrm{R}$.

Genotyping and map construction. Genomic DNA was isolated from young leaf tissue of the parents and populations $\left(180 \mathrm{~F}_{2}\right.$ and 203 RILs) using ChargeSwitch gDNA Plant Kits (Life Technologies,
Carlsbad, CA). Library preparation (96-plex; ApeKI) and genotyping by sequencing (GBS; Elshire et al. 2011) were completed at Cornell University, Institute for Genomic Diversity Facility. Fragments (100 bp, single-end reads) were sequenced on an Illumina HiSeq 2000/2500.

Single nucleotide polymorphism (SNP) calling and map construction were completed for each population $\left(\mathrm{F}_{2: 3}\right.$ and RIL) independently. Default settings were used in each software package unless otherwise stated. A reference-quality genome assembly and annotation of USVL246-FR2 (the resistant parent) was recently completed (unpublished). Sequenced fragments were aligned to the USVL246-FR2 reference genome using the Burrows-Wheeler aligner version 0.5.9 ( $\mathrm{Li}$ and Durbin 2009, 2010). SNPs were called with the GBS version 2 pipeline of TASSEL 5.2.30 (Bradbury et al. 2007; Glaubitz et al. 2014). SNPs with a minor allele frequency of less than 0.01 and/or more than $90 \%$ missing data were removed as likely genotyping errors using VCFtools version 0.1.15 (Danecek et al. 2011). Missing allele calls were imputed in the $F_{2}$ population with the window LD algorithm in the FSFHap (Swarts et al. 2014) plugin of TASSEL version 5.2.19 (Bradbury et al. 2007). The proportion of missing genotypic data in the RIL population was reduced with imputation in BEAGLE version 4.1 (Browning and Browning 2007, 2016) without a reference panel using default settings with 10 burn-in iterations and 15 phasing iterations. Allele calls were recoded into parental genotypes with the $\mathrm{ABH}$ plugin of TASSEL. Additional quality filtering steps were performed in the qtl package (Broman et al. 2003) of R. SNPs with identical segregation patterns across the population were binned. Each pair of genotypes was compared with search for identical twins in each population. Twins were only identified in the RIL population, and one line of each pair was removed at random. SNPs with severe segregation distortion $\left(P<1 \times 10^{-10}\right)$, as assessed by $\chi^{2}$ test, were removed from the dataset.

Genetic linkage maps were constructed in the qtl package of $\mathrm{R}$ according to the Lander-Green algorithm (Lander and Green 1987 ) with a maximum recombination frequency of 0.35 and minimum logarithm of odds (LOD) scores of $10\left(\mathrm{~F}_{2}\right.$ map) and 7 (RIL map). Recombination fractions were converted to genetic distances with the Kosambi mapping function (Kosambi 1943).

Genetic mapping of QTLs. QTLs were identified for Fon race 1 resistance by mapping mean survival for each test separately and combined. Multiple QTL mapping was completed with the stepwiseqtl function (Broman and Sen 2009; Broman and Speed 2002; Zeng et al. 1999) of Rqtl (Broman et al. 2003) using HaleyKnott regression (Haley and Knott 1992). The optimal QTL model was chosen based upon the highest penalized LOD score (Manichaikul et al. 2009) after forward and backward selection with the stepwiseqtl package. Penalties for model selection and the genomewide significance threshold $(\alpha=0.05 ; \mathrm{LOD}=3.8)$ were determined through 1,000 permutations of a two-dimensional, two-QTL genome scan with the function scantwo. Standard interval mapping with Haley-Knott regression (Haley and Knott 1992) with the scanone function, followed by forward selection, was used to visualize multiple QTL models of up to five QTLs. Nonparametric QTL mapping (Kruglyak and Lander 1995; Kruskal and Wallis 1952) was used to confirm QTLs because the distribution Fon race 1 resistance was only approximately normal. Predicted protein sequences of candidate genes within the 1.5-LOD intervals of significant QTLs were obtained from the unpublished draft genome annotation of USVL246-FR2.

\section{Results}

Fon race 1 resistance. Although $180 \mathrm{~F}_{2: 3}$ individuals and 203 RILs were genotyped to make the genetic maps, lack of germination and insufficient seed reduced the samples phenotyped to 177 $\mathrm{F}_{2: 3}$ families and 173 RILs. The distribution of mean survival across the $\mathrm{F}_{2: 3}$ families was continuous and approximately normal with an overall population minimum, mean, and maximum of 0 , 31.6 , and $77.8 \%$, respectively (Fig. 1). The mean survival of the susceptible parent (USVL114) was higher than expected at 
$22.0 \%$, owing to an intermediate resistance response $(52.8 \%)$ in test 3 (Table 1). The line mean of the resistant parent, although substantially higher than the population mean (31.7\%), was only moderately resistant at $56.8 \%$ survival. The lower-thanexpected survival mean of USVL246-FR2 was owing to much lower survival in replicate 2 of test $1(11.1 \%)$ compared with the other five replicates, which ranged from 40 to $88.9 \%$. The $\mathrm{F}_{1}$ showed an intermediate response to Fon race 1 with a mean survival of $46.5 \%$ and a range of 21.1 to $65 \%$ across tests. Correlation of survival family means between the three tests (test 1 versus 2,2 versus 3 , and 1 versus 3 ), although highly significant for all comparisons $(P<0.0001)$, was intermediate with Pearson's correlation coefficients $(r)$ of $0.42,0.39$, and 0.40 , respectively. Broad-sense heritability of Fon race 1 resistance was low for the $\mathrm{F}_{2: 3}$ population $\left(\mathrm{H}^{2}=0.26\right)$ with the majority of the variation attributable to environment (Table 2), evident in the wide variation in test means (Table 1). There was also significant heterogeneity of variances between the tests $(P<0.0001)$, so in addition to family means across tests, within-test family means were used as traits for QTL mapping.

Mean disease severity $(1=$ healthy to $5=$ dead $)$ across the RIL population also approximated a normal distribution with a range of 1.1 to 4 and a mean of 2.5 (Fig. 1). The parental disease severity means, USVL246-FR2 (1.5) and USVL114 (3.9), fell in the expected tails of the distribution, and the $F_{1}(2.5)$ continued to have an intermediate disease response (Fig. 1).

Percent survival of the differentials confirmed the race 1 designation of the isolate used for inoculations. Calhoun Gray, which is known to be resistant to Fon race 1 and susceptible to Fon race 2 (Martyn and Netzer 1991), supported race identity with $74.7 \%$ mean survival for Fon race 1. Additionally, PCR using the FonSIX6 primers described
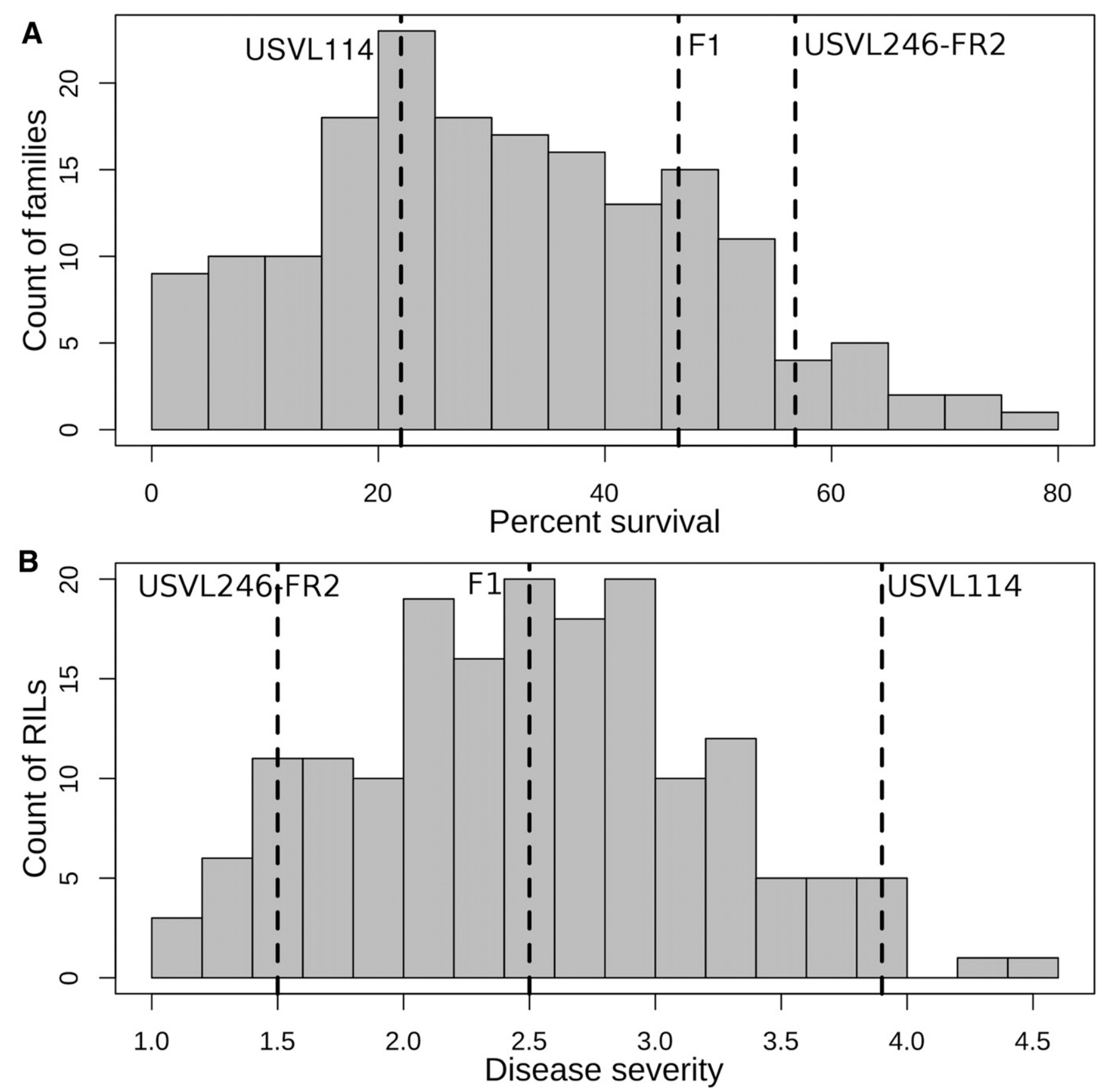

Fig. 1. Histograms of $\mathbf{A}$, percent survival of each $\mathrm{F}_{2: 3}$ family $(n=170)$ and $\mathbf{B}$, disease severity scores ( $1=$ healthy to $5=$ dead) of recombinant inbred lines $(\mathrm{RILs})$, averaged across tests in response to inoculation with Fusarium oxysporum f. sp. niveum race 1. The vertical lines indicate the average percent survival of the resistant (USVL246-FR2) and susceptible (USVL114) parents and $F_{1}$. 
by Niu et al. (2016) also verified the race 1 status of the isolate used (data not shown). Survival means were lower across the $\mathrm{F}_{2: 3}$ population and for both parents in response to inoculation with Fon race 1 (population mean $=31.6 \%$ ) compared with Fon race 2 (population mean $=45.8 \%$; Branham et al. 2017) $($ Table 1). Correlation of percent survival family means between the two races was only borderline significant $(P=0.055)$ and weak $(r=0.15)$.

Genotyping and genetic maps. $F_{2: 3}$ population. Genotyping by sequencing of the parents, $\mathrm{F}_{1}$, and $\mathrm{F}_{2: 3}$ population generated 417 million barcoded reads. The reads grouped into 131,217 tags, but $4.6 \%$ did not map to the genome. SNP calling produced 11,132 raw SNPs, which were filtered and binned to a set of 1,455 binned SNPs that were used for map construction. Imputation reduced the percentage of missing data from 21.3 to $2.3 \%$. No identical twins were identified in the $\mathrm{F}_{2}$ : 3 population. Eleven linkage groups (corresponding to the 11 chromosomes of citron melon) were formed with a total map length of 1,278.8 cM (Supplementary Table 1). SNPs were spaced $0.9 \mathrm{cM}$ on average, with a maximum distance of $11.3 \mathrm{cM}$ between adjacent SNPs.

RIL population. More than 916 million barcoded reads were output from GBS and grouped into 203,282 tags (94.4\% mapped to the genome). An initial set of 30,818 SNPs were identified and subsequently filtered and binned to 2,143 binned SNPs for map construction. Missing data were reduced from 23.4 to $1.9 \%$ through imputation. Three sets of identical twins were found, and one was removed from each set at random from further analysis ( $n=200$ RILs remaining). The genetic map consisted of 11 linkage groups with a map length of 1,188.9 cM (Supplementary Table 2). All linkage groups were well covered, with a minimum of 110 binned SNPs per linkage group.

Fon race 1 resistance QTLs. The QTL model of maximum penalized LOD score selected for both the $\mathrm{F}_{2: 3}$ and RIL populations, whether using sample means per test or across tests, consisted of a single significant QTL on chromosome 9 of citron melon ( $q$ Fonl9; Fig. 2). The scan for the first QTL location consisted of multiple peaks above the genome-wide significance threshold, but after controlling for the effect of the initial QTL, the other peaks did not pass the significance threshold in subsequent scans for additional QTLs (Fig. 2). The association of $q$ Fon $1-9$ with Fon race 1 resistance in both populations and all tests was confirmed by nonparametric QTL mapping. Although the position of the QTL peak varied, the 1.5-LOD intervals overlapped for all traits tested, so it was therefore considered to be the same QTL (Table 3). The LOD score and percentage of the variation in Fon race 1 resistance explained by the QTL varied from 5.6 to 10.7 and from 14.1 to $24.7 \%$, respectively. qFon $1-9$ explained nearly all of the variation in resistance expected to be attributable to genotype (26\%) given the heritability. As expected, USVL246-FR2 (the resistant parent) contributed the resistance allele for qFon1-9. Genotypic percentage survival means of $42.2 \%$ (homozygous resistant), $33.6 \%$ (heterozygous), and $19.3 \%$ (homozygous susceptible) at the peak SNP $(18,953,614 \mathrm{bp})$, along with the intermediate phenotype of the $\mathrm{F}_{1}$, suggest incomplete dominance of the resistance phenotype for $q$ Fon1-9. The 1.5-LOD interval of $q$ Fon 1-9 extended approximately $10 \mathrm{cM}$ for both populations, with the corresponding genomic regions completely overlapping (Table 3 ). The RIL physical interval (10.6 $\mathrm{Mb}$ ), was more narrow than the $\mathrm{F}_{2: 3}$ interval owing to additional recombination events. The RIL phenotyping was, however, based upon only one test, so the broader $\mathrm{F}_{2: 3}$ interval of $13,674,645$ to $26,224,294$ bp was used to identify 264 candidate genes collocated with qFon1-9 (Supplementary Table 3).

\section{Discussion}

Although the family survival means in response to inoculation with Fon race 1 cover a broad range, the overall $\mathrm{F}_{2: 3}$ population and resistant parent means were low. This $C$. amarus population was previously tested for resistance to Fon race 2 (Branham et al. 2017) and had a $10 \%$ higher population survival mean. A direct comparison cannot be made, however, because the trials were done separately and a significant fraction of the variation in disease response was environmentally controlled in both studies. The low survival means after inoculation with Fon race 1 can be attributed to wide variation between tests. A QTL mapping study of Fon race 1 resistance in a C. lanatus $\mathrm{F}_{2: 3}$ population also showed a drastic difference in magnitude of disease severity between tests (Meru and McGregor 2016).

Despite the variation observed between tests, the QTL on chromosome 9 (qFon1-9) was consistently identified for every test of both populations. qFon 1-9 represents a novel source of resistance to Fon race 1. Previous QTL mapping studies of Fon race 1 resistance identified a single major QTL on chromosome 1 in both $C$. amarus (Ren et al. 2015) and C. lanatus (Lambel et al. 2014; Meru and McGregor 2016). Lambel et al. (2014) found several QTLs of small effect in addition to the major QTL, including one with confidence intervals that overlapped those of qFon1-9. The peak associations for the QTLs on chromosome 9 are nearly $10 \mathrm{Mbp}$ apart, but the positions are based upon different species' genomes with wide confidence intervals, so it is unclear whether they collocate. A QTL study of Fon race 2 resistance in the $\mathrm{F}_{2: 3}$ population evaluated herein also identified a QTL on chromosome 9 with 1.5-LOD intervals that overlap those of qFon1-9. The possibility that $q$ Fon 1-9 confers resistance to Fusarium wilt in a non-race-specific manner cannot be confirmed, because the causal polymorphism underlying the QTL is unknown. Increased QTL resolution is needed to clarify the underlying causal genes, which may be achieved through fine mapping with larger populations and more tests of resistance per study.

Different forma specialis of $F$. oxysporum infect a wide range of plant host species. Two main categories of genes, nucleotide binding site leucine rich repeats and receptor-like protein kinases (RLKs), have been shown to confer resistance to $F$. oxysporum. RLKs, validated through cloning and transgenic complementation, conferred resistance to $F$. oxysporum f. sp. matthioli in Arabidopsis thaliana (Cole and Diener 2013) and F. oxysporum f. sp. lycopersicum in tomato (Catanzariti et al. 2015). The validated RLK (RFO1) in A. thaliana may provide broad-spectrum resistance to multiple f. sp., because an rfol loss-of-function mutant was more susceptible than the wild type to $F$. oxysporum f. sp. matthioli, f. sp. conglutinans, and $\mathrm{f}$. sp. raphanin (Diener and Ausubel 2005). Genes encoding seven predicted RLKs were located within the 1.5-LOD interval of qFon 1-9 and are strong candidates for Fon race 1 resistance, possibly in the form of broad-spectrum, non-race-specific resistance.

The identification of a QTL associated with resistance to Fon race 1 on chromosome 9 of citron melon represents a novel genetic source of resistance to this devastating soilborne phytopathogen. With limited means of cultural or chemical control measures for Fon, host-plant

Table 1. Disease response means of $\mathrm{F}_{2: 3}$ (percent survival) and recombinant inbred line (RIL) (disease severity) populations, parents, and $\mathrm{F}_{1}$ of Citrullus amarus $(N=170)$ after artificial inoculation with Fusarium oxysporum f. sp. niveum race 1

\begin{tabular}{lccccc}
\hline $\begin{array}{l}\text { Experimental } \\
\text { unit }\end{array}$ & Population & $\begin{array}{c}\text { Population } \\
\text { mean }\end{array}$ & $\begin{array}{c}\text { USVL246- } \\
\text { FR2 }\end{array}$ & USVL114 & F $_{\mathbf{1}}$ \\
\hline Overall & $\mathrm{F}_{2: 3}$ & 31.6 & 56.8 & 22.0 & 46.5 \\
Test 1 & $\mathrm{F}_{2: 3}$ & 28.1 & 25.6 & 13.3 & 53.3 \\
Test 2 & $\mathrm{F}_{2: 3}$ & 42.9 & 79.4 & 0 & 65.0 \\
Test 3 & $\mathrm{F}_{2: 3}$ & 23.7 & 65.3 & 52.8 & 21.1 \\
Overall & $\mathrm{RIL}$ & 2.5 & 1.5 & 3.9 & 2.5 \\
\hline
\end{tabular}

Table 2. Variance components and heritability $\left(\mathrm{H}^{2}\right)$ of percent survival of an $\mathrm{F}_{2: 3}$ population of Citrullus amarus in response to artificial inoculation with Fusarium oxysporum f. sp. niveum race 1

\begin{tabular}{lccc}
\hline Variance component & Variance & $\boldsymbol{\%}_{\mathbf{P}} \mathbf{V}^{\mathbf{a}}$ & Standard error \\
\hline Family & 171.5 & 25.8 & 29.3 \\
Test & 107.7 & 16.2 & 113.5 \\
Family $\times$ test & 73.0 & 11.0 & 21.9 \\
Replicate within test & 8.3 & 1.2 & 8.5 \\
Residual & 304.4 & 45.8 & 20.5 \\
Family/total $\left(\mathrm{H}^{2}\right)$ & 0.26 & $\mathrm{NA}^{\mathrm{b}}$ & $\mathrm{NA}$ \\
\hline
\end{tabular}

a Percent of the total phenotypic variance.

b Not applicable. 

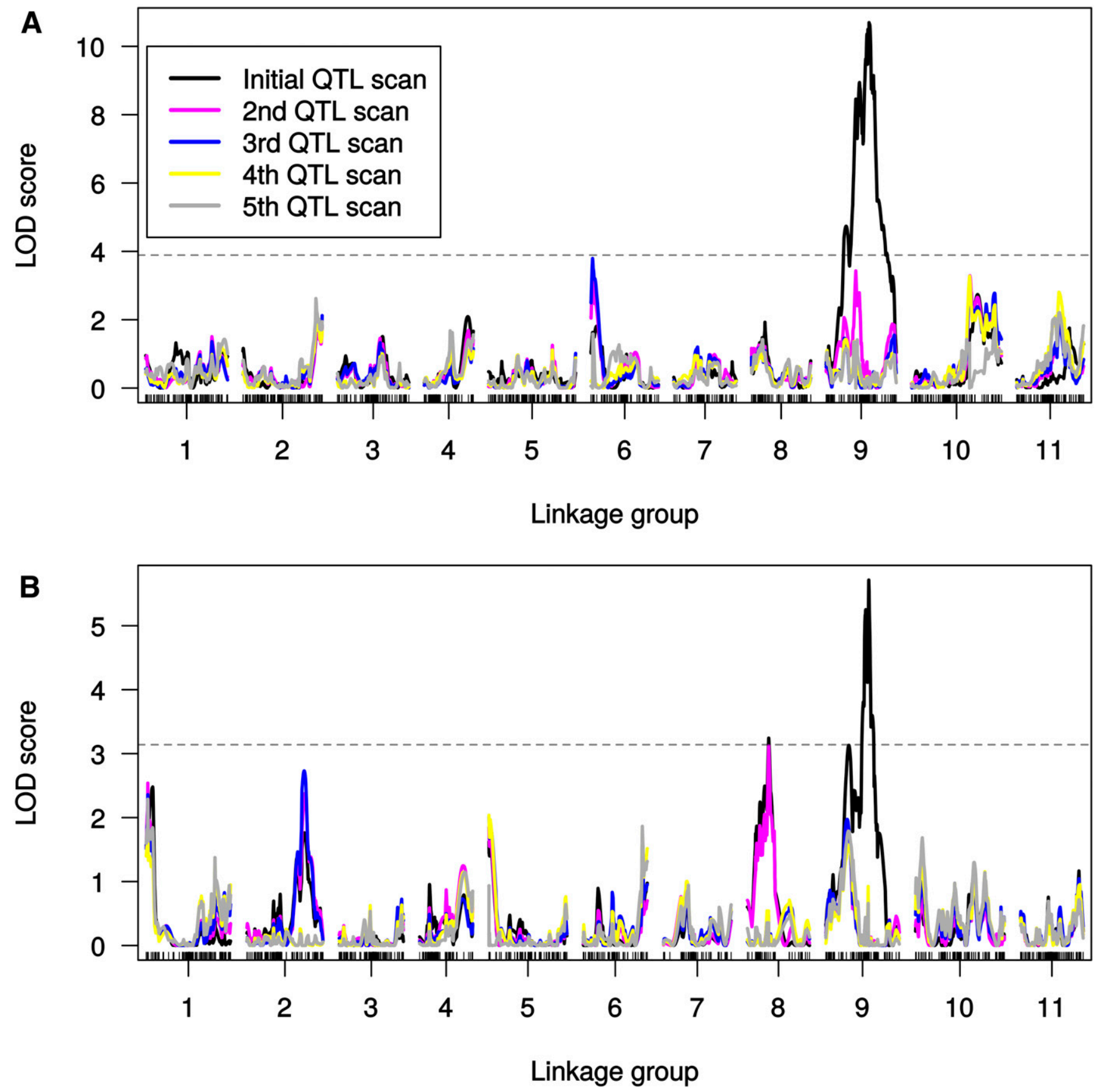

Fig. 2. Logarithm of odds (LOD) scores for model selection up to five quantitative trait loci (QTLs) for A, mean percent survival across tests in the $F_{2 \cdot 3}$ population and $B$, mean disease severity in the recombinant inbred line population in response to inoculation with Fusarium oxysporum $\mathrm{f}$. sp. niveum race 1. The initial scan shows the likelihood of the first QTL being located at each single nucleotide polymorphism in the genome (linkage group = chromosome), with subsequent scans showing the LOD of an additional QTL with the effects of the previous QTL(s) controlled for in the model. The dashed line marks the genome-wide significance threshold.

Table 3. Single quantitative trait loci (QTLs) on linkage group (chromosome) 9 associated with Fusarium oxysporum f. sp. niveum race 1 resistance means from across and within tests of genetic populations of citron melon (Citrullus amarus)

\begin{tabular}{llccrrrrr}
\hline Population & Dataset mean & Peak $(\mathbf{c M})$ & Range $(\mathbf{M b})^{\mathbf{a}}$ & LOD $^{\mathbf{b}}$ & $\boldsymbol{\%}_{\mathbf{P}} \mathbf{c}$ & $\boldsymbol{P}_{\text {value }}$ & Additive $^{\mathbf{d}}$ & Dominance $^{\mathbf{e}}$ \\
\hline $\mathrm{F}_{2: 3}$ & Across 3 tests & 70.1 & $13.7-26.2$ & 10.7 & 24.7 & $3.1 \times 10^{-11}$ & 11.4 & -2.9 \\
$\mathrm{~F}_{2: 3}$ & Test 1 & 56.0 & $10.0-26.2$ & 8.5 & 20.8 & $4.8 \times 10^{-9}$ & 12.3 & 5.2 \\
$\mathrm{~F}_{2: 3}$ & Test 2 & 71.6 & $8.9-29.5$ & 5.6 & 14.3 & $2.9 \times 10^{-6}$ & 10.5 & -6.1 \\
$\mathrm{~F}_{2: 3}$ & Test 3 & 79.5 & $13.7-33.1$ & 6.3 & 22.8 & $7.5 \times 10^{-7}$ & 10.3 & 3.7 \\
RIL $^{\mathrm{f}}$ & Test 1 & 66.0 & $15.6-26.1$ & 5.7 & 14.1 & $3.5 \times 10^{-7}$ & -0.26 & NA $^{\mathrm{g}}$ \\
\hline
\end{tabular}

a Physical region of the genome corresponding to the 1.5-LOD interval of the QTL.

${ }^{\mathrm{b}}$ Logarithm of odds.

${ }^{c}$ Percent of the phenotypic variation explained by the QTL.

${ }^{d}$ Additive effect of the QTL.

${ }^{\mathrm{e}}$ Dominance effect of the QTL.

${ }^{\mathrm{f}}$ Recombinant inbred line.

g Not applicable. 
resistance is extremely important in any strategy to address this pathogen. To delay or prevent loss of resistance, the introgression of multiple genetic sources of resistance in a single cultivar (gene pyramiding) is a goal for many breeders and seed producers. The current genetic source of Fon race 1 resistance in both cultivated and citron melon is found on chromosome 1 . With this new source of resistance on chromosome 9 collocating with a Fon race 2 resistance QTL, watermelon breeders may be able to apply gene pyramiding of resistance to Fon race 2 with multiple sources to Fon race 1.

\section{Literature Cited}

Bradbury, P. J., Zhang, Z., Kroon, D. E., Casstevens, T. M., Ramdoss, Y., and Buckler, E. S. 2007. TASSEL: Software for association mapping of complex traits in diverse samples. Bioinformatics 23:2633-2635.

Branham, S. E., Levi, A., Farnham, M. W., and Wechter, W. P. 2017. A GBS-SNPbased linkage map and quantitative trait loci (QTL) associated with resistance to Fusarium oxysporum f. sp. niveum race 2 identified in Citrullus lanatus var. citroides. Theor. Appl. Genet. 130:319-330.

Broman, K. W., and Sen, S. 2009. A Guide to QTL Mapping with R/qtl. Springer, New York, NY.

Broman, K. W., and Speed, T. 2002. A model selection approach for the identification of quantitative trait loci in experimental crosses. J. R. Stat. Soc. B 64:641-656, 731-775.

Broman, K. W., Wu, H., Sen, S., and Churchill, G. A. 2003. R/qtl: QTL mapping in experimental crosses. Bioinformatics 19:889-890.

Browning, B. L., and Browning, S. R. 2016. Genotype imputation with millions of reference samples. Am. J. Hum. Genet. 98:116-126.

Browning, S. R., and Browning, B. L. 2007. Rapid and accurate haplotype phasing and missing-data inference for whole-genome association studies by use of localized haplotype clustering. Am. J. Hum. Genet. 81:1084-1097.

Catanzariti, A. M., Lim, G. T. T., and Jones, D. A. 2015. The tomato I-3 gene: A novel gene for resistance to Fusarium wilt disease. New Phytol. 207:106-118.

Chomicki, G., and Renner, S. S. 2015. Watermelon origin solved with molecular phylogenetics including Linnaean material: Another example of museomics. New Phytol. 205:526-532.

Cole, S. J., and Diener, A. C. 2013. Diversity in receptor-like kinase genes is a major determinant of quantitative resistance to Fusarium oxysporum f. sp. matthioli. New Phytol. 200:172-184.

Colla, G., Rouphael, Y., Cardarelli, M., and Rea, E. 2006. Effect of salinity on yield, fruit quality, leaf gas exchange, and mineral composition of grafted watermelon plants. HortScience 41:622-627.

Danecek, P., Auton, A., Abecasis, G., Albers, C. A., Banks, E., DePristo, M. A., Handsaker, R. E., Lunter, G., Marth, G. T., Sherry, S. T., McVean, G., Durbin, R., and 1000 Genomes Project Analysis Group. 2011. The variant call format and VCFtools. Bioinformatics 27:2156-2158.

Diener, A. C., and Ausubel, F. M. 2005. Resistance to Fusarium oxysporum 1, a dominant Arabidopsis disease-resistance gene, is not race specific. Genetics 171:305-321.

Elshire, R. J., Glaubitz, J. C., Sun, Q., Poland, J. A., Kawamoto, A., Buckler, E. S., and Mitchell, S. E. 2011. A robust, simple genotyping-by-sequencing (GBS) approach for high diversity species. PLoS One 6:e19379.

Everts, K. L., Egel, D. S., Langston, D., and Zhou, X. G. 2014. Chemical management of Fusarium wilt of watermelon. Crop Prot. 66:114-119.

Everts, K. L., and Himmelstein, J. C. 2015. Fusarium wilt of watermelon: Towards sustainable management of a re-emerging plant disease. Crop Prot. 73:93-99.

Fox, J., and Weisberg, S. 2011. An R Companion to Applied Regression, 2nd Ed. Sage, Thousand Oaks, CA.

Gilmour, A. R., Gogel, B. J., Cullis, B. R., and Thompson, R. 2009. ASReml User Guide Release 3.0. VSN International, Hemel Hempstead, U.K.

Glaubitz, J. C., Casstevens, T. M., Lu, F., Harriman, J., Elshire, R. J., Sun, Q., and Buckler, E. S. 2014. TASSEL-GBS: A high capacity genotyping by sequencing analysis pipeline. PLoS One 9:e90346.

Guo, S., Zhang, J., Sun, H., Salse, J., Lucas, W. J., Zhang, H., Zheng, Y., Mao, L., Ren, Y.,Wang, Z., Min, J., Guo, X., Murat, F., Ham, B. K., Zhang, Z., Gao, S., Huang, M., Xu, Y., Zhong, S., Bombarely, A., Mueller, L. A., Zhao, H., He, H., Zhang, Y., Zhang, Z., Huang, S., Tan, T., Pang, E., Lin, K., Hu, Q., Kuang, H., Ni, P., Wang, B., Liu, J., Kou, Q., Hou, W., Zou, X., Jiang, J., Gong, G., Klee, K., Schoof, H., Huang, Y., Hu, X., Dong, S., Liang, D., Wang, J., Wu, K., Xia, Y., Zhao, X., Zheng, Z., Xing, M., Liang, X., Huang, B., Lv, T., Wang, J., Yin, Y., Yi, H., Li, R., Wu, M., Levi, A., Zhang, X., Giovannoni, J. J., Wang, J., Li, Y., Fei, Z., Xu, Y. 2013. The draft genome of watermelon (Citrullus lanatus) and resequencing of 20 diverse accessions. Nat. Genet. 45:51-58.

Haley, C. S., and Knott, S. A. 1992. A simple regression method for mapping quantitative trait loci in line crosses using flanking markers. Heredity 69:315-324.

Keinath, A. P., and Hassell, R. L. 2014a. Control of Fusarium wilt of watermelon by grafting onto bottlegourd or interspecific hybrid squash despite colonization of the rootstocks by Fusarium oxysporum. Plant Dis. 98:255-266.

Keinath, A. P., and Hassell, R. L. 2014b. Suppression of Fusarium wilt caused by Fusarium oxysporum f. sp. niveum race 2 on grafted triploid watermelon. Plant Dis. 98:1326-1332.
Kiyosawa, S. 1982. Genetics and epidemiological modeling of breakdown of plant disease resistance. Annu. Rev. Phytopathol. 20:93-117.

Kleczewski, N. M., and Egel, D. S. 2011. A diagnostic guide for Fusarium wilt of watermelon. Online publication. Plant Health Prog. 12. doi: 10.1094/PHP-20111129-01-DG.

Kosambi, D. D. 1943. The estimation of map distances from recombination values. Ann. Eugen. 12:172-175.

Kruglyak, L., and Lander, E. S. 1995. A nonparametric approach for mapping quantitative trait loci. Genetics 139:1421-1428.

Kruskal, W. H., and Wallis, W. A. 1952. Use of ranks in one-criterion variance analysis. J. Am. Stat. Assoc. 47:583-621.

Lambel, S., Lanini, B., Vivoda, E., Fauve, J., Wechter, W. P., Harris-Shultz, K. R., Massey, L., Levi, A. 2014. A major QTL associated with Fusarium oxysporum race 1 resistance identified in genetic populations derived from closely related watermelon lines using selective genotyping and genotyping-by-sequencing for SNP discovery. Theor. Appl. Genet. 127:2105-2115.

Lander, E. S., and Green, P. 1987. Construction of multilocus genetic linkage maps in humans. Proc. Natl. Acad. Sci. U.S.A. 84:2363-2367.

Levene, H. 1960. Robust tests for equality of variance. Pages 278-292 in: Contributions to Probability and Statistics: Essays in Honor of Harold Hotelling. I. Olkin, S. G. Ghurye, W. Hoeffeling, W. G. Madow, and H. B. Mann, eds. Stanford University Press, Menlo Park, CA.

Levi, A., Thies, J. A., Wechter, W. P., Harrison, H. F., Simmons, A. M., Reddy, U. K., Nimmakayala, P., and Fei, Z. 2013. High frequency oligonucleotides: Targeting active gene (HFO-TAG) markers revealed wide genetic diversity among Citrullus spp. accessions useful for enhancing disease or pest resistance in watermelon cultivars. Genet. Resour. Crop Evol. 60: 427-440.

Levi, A., Thomas, C. E., Wehner, T. C., and Zhang, X. 2001. Low genetic diversity indicates the need to broaden the genetic base of cultivated watermelon. HortScience 36:1096-1101.

Li, H., and Durbin, R. 2009. Fast and accurate short read alignment with BurrowsWheeler transform. Bioinformatics 25:1754-1760.

Li, H., and Durbin, R. 2010. Fast and accurate long-read alignment with BurrowsWheeler transform. Bioinformatics 26:589-595.

Manichaikul, A., Moon, J. Y., Sen, Ś., Yandell, B. S., and Broman, K. W. 2009. A model selection approach for the identification of quantitative trait loci in experimental crosses, allowing epistasis. Genetics 181:1077-1086.

Martyn, R. D. 1987. Fusarium oxysporum f. sp. niveum race 2: A highly aggressive race new to the United States. Plant Dis. 71:233-236.

Martyn, R. D., and Bruton, B. D. 1989. An initial survey of the United States for races of Fusarium oxysporum f. sp. niveum. HortScience 24:696-698.

Martyn, R. D., and Netzer, D. 1991. Resistance to races 0, 1, and 2 of Fusarium wilt of watermelon in Citrullus sp. PI-296341-FR. HortScience 26:429-432.

Meru, G., and McGregor, C. 2016. Genotyping by sequencing for SNP discovery and genetic mapping of resistance to race 1 of Fusarium oxysporum in watermelon. Sci. Hortic. (Amsterdam) 209:31-40.

Netzer, D. 1976. Physiological races of soil population levels of Fusarium wilt of watermelon. Phytoparasitica 4:131-136.

Netzer, D., and Martyn, R. D. 1989. PI 296341, a source of resistance in watermelon to race 2 of Fusarium oxysporum $\mathrm{f}$. sp. niveum. Plant Dis. 73:518.

Netzer, D., and Weintall, C. H. 1980. Inheritance of resistance in watermelon to race 1 of Fusarium oxysporum f. sp. niveum. Plant Dis. 64:853-854.

Niu, X., Zhao, X., Ling, K.-S., Levi, A., Sun, Y., and Fan, M. 2016. The FonSIX6 gene acts as an avirulence effector in the Fusarium oxysporum f. sp. niveum-watermelon pathosystem. Sci. Rep. 6:28146.

R Core Team. 2017. R: A Language and Environment for Statistical Computing. R Foundation for Statistical Computing, Vienna, Austria.

Ren, Y., Jiao, D., Gong, G., Zhang, H., Guo, S., Zhang, J., and Xu, Y. 2015. Genetic analysis and chromosome mapping of resistance to Fusarium oxysporum f. sp. niveum (FON) race 1 and race 2 in watermelon (Citrullus lanatus L.). Mol. Breed. 35:183.

Staskawicz, B. J., Ausubel, F. M., Baker, B. J., Ellis, J. G., and Jones, J. D. G. 1995. Molecular genetics of plant disease resistance. Science 268:661-667.

Swarts, K., Li, H., Romero Navarro, J. A., An, D., Romay, M. C., Hearne, S, Acharya, C., Glaubitz, J. C., Mitchell, S., Elshire, R. J., Buckler, E. S., and Bradbury, P. J. 2014. Novel methods to optimize genotypic imputation for lowcoverage, next-generation sequence data in crop plants. Plant Genome 7. doi. org/10.3835/plantgenome2014.05.0023.

U.S. Department of Agriculture, Economic Research Service (USDA-ERS). 2017. Fruit and Tree Nuts Yearbook. USDA, Washington, DC.

Wechter, W. P., Kousik, C., McMillan, M., and Levi, A. 2012. Identification of resistance to Fusarium oxysporum f. sp. niveum race 2 in Citrullus lanatus var. citroides plant introductions. HortScience 47:334-338.

Wechter, W. P., McMillan, M., Farnham, M. W., and Levi, A. 2016. Watermelon germplasm lines USVL246-FR2 and USVL252-FR2 tolerant to Fusarium oxysporum f. sp. niveum race 2. HortScience 51:1065-1067.

Zeng, Z. B., Kao, C. H., and Basten, C. J. 1999. Estimating the genetic architecture of quantitative traits. Genet. Res. 74:279-289.

Zhou, X. G., Everts, K. L., and Bruton, B. D. 2010. Race 3, a new and highly virulent race of Fusarium oxysporum f. sp. niveum causing Fusarium wilt in watermelon. Plant Dis. 94:92-98. 